\author{
ОДНОНАПРАВЛЕННАЯ РОТАЦИЯ БЛОКОВ \\ ФУНДАМЕНТА КАК МЕХАНИЗМ СОКРАЩЕНИЯ \\ РАЗМЕРОВ ЖЕСТКОГО ОСНОВАНИЯ \\ СКЛАДЧАТОЙ СИСТЕМЫ \\ (НА ПРИМЕРЕ ЦЕНТРАЛЬНОГО КАВКАЗА) \\ ЧАСТЬ № $2^{1}$ \\ Ю.А. Киричко
}

\begin{abstract}
Аннотация. Для киммерийского и альпийского этапов развития Центрального Кавказа (ЦК) рассматривается механизм формирования складчатости, учитывающий блоковый характер строения фундамента, условия залегания реликтов чехла и особенности проявления складчатых деформаций. Определяющим в фрормировании складчатости является однонаправленная ротация жестких блоков фрундамента. Механизм ротации рассматривается в рамках трехслойной модели земной коры. Формирование складчатости при вращении блоков фунндамента обусловлено наличием сил горизонтального сжатия, сокращением поверхности жесткого основания и наличием синхронно действующих разнонаправленных вертикальных сил действующих на границах блоков. В пределах ЦК выделяется 10 основных крупных блоков, имеющих признаки рассматриваемого механизма, значительная часть которых ранее выделялась в качестве поднятий и депрессий.

Ключевые слова: Центральный Кавказ, фундамент, чехол, депрессии, впадины, поднятия, механизм формирования складчатости, сокращение размеров жесткого основания, ротация блоков фрундамента, динамический разлом.
\end{abstract}

\section{ПРЕДПОСЫЛКИ И УСЛОВИЯ РЕАЛИЗАЦИИ РАССМАТРИВАЕМОЙ МОДЕЛИ}

Необходимыми условиями реализации модели являются холодное состояние верхней коры, глубинный - «сквозной» характер разломов, ограничивающих блоки фрундамента, наличие сил сжатия в коре и магматического очага или реологически высокопластичных пород в ее основании.

Предпосылки этих условий в регионе Большого Кавказа существуют. Так, в пользу глубинности зон разломов свидетельствует их значительная (2-4 км и более) вертикальная амплитуда, что дает основание предполагать их существование в качестве разрывов до глубин 10-12 км, и далее в виде зон вязкого течения; отрывочные данные геофизических наблюдений (гравиметровые по Пшекиш-Тырныаузскому разлому дают основание говорить о наличии плотностных перепадов по нему до глубин не менее 6-8 км) [22], приуроченность к ним зон бластомиллонитов, как индикаторов разломных зон глубинного заложения [18]; последние фрагментами достоверно фриксируются к северу от Северо-Штулинского, Пшекиш-Тырныаузского и Главного Кавказского разломов.
Субмеридиональное тангенцальное сжатие, общее для всего Кавказа, как причина образования складчатой системы отмечается в многочисленных работах геологов с 30-х годов и до настоящего времени [8, 15]. С ним связывается сокращение литосферы и образование основных структурных парагенезов - структур сжатия и правого сдвига. Элементы этих структурных парагенезов, по данным Л.М. Расцветаева, развиваются от ранней юры до современной эпохи $[8,9]$.

Базальтоидный магматизм Казбекского и Хуламского комплексов несомненно свидетельствует о существовании глубинного очага этих магм на киммерийском и альпийском этапах тектогенеза. Для поздней фразы более характерен кислый андезит-риолитовый вулканизм. Термодинамические расчеты показывают, что глубины генерации базальтовых магм для Кавказа составляют порядка 35-40 км [28], что хорошо согласуется с предлагаемой моделью. Процессы кимерийского и альпийского тектогенеза на Большом Кавказе осуществлялись в условиях холодной верхней коры, на что указывает региональный метаморфизм низких ступеней в пределах Перевальной зоны и отсутствие К-Агдатировок третичного возраста $[18,19]$.

* Киричко Юрий Александрович - главный специалист Департамента геологии и минеральных ресурсов по Северо-Кавказскому фредеральному округу (ykirichko@gmail.com).

${ }^{1}$ Первую часть данной статьи см. в предыдущем номере журнала. 


\section{ОСНОВНЫЕ БЛОКИ И ИСТОРИЯ ТЕКТОНИЧЕСКОГО РАЗВИТИЯ ЦЕНТРАЛЬНОГО КАВКАЗА}

В рамках рассматриваемой ротационно-блоковой модели применительно к Центральному Кавказу в пределах зоны Главного хребта (в полосе от р. Белой на западе до р. Терек на востоке), в общем виде можно наметить основные структурные элементы и последовательность процессов формирования системы.

Характерными особенностями выделяемых здесь структурных элементов (блоков) являются:

- в общих контурах линзовидно-ромбоидальная или линзовидная форма блоков в поверхностном сечении;

- ограничения блоков (в пределах области развития кристаллических пород) по контуру разрывными нарушениями или узкими складчато-разрывными зонами с южной и юго-западной стороны и реликтовыми останцами (депрессиями) или фррагментами нижнее-среднеюрских пород - с северной, северо-восточной стороны;

- амплитуда ограничивающих нарушений уменьшается от центральной части блоков к его замыканиям (как в северо-западном, так и в юговосточном направлениях).

В пределах рассматриваемой территории Центрального Кавказа можно выделить 10 основных крупных блоков [рuс. 6], отвечающих приведенным выше особенностям, значительная часть которых ранее выделялась в качестве поднятий и депрессий, в связи с чем в названиях блоков соблюдена преемственность по отношению к выделявшимся ранее названиям структур. С запада на восток выделяются:

- Чугушский блок-І (включающий Чугушское поднятие и Псеашхинскую депрессию);

- Бамбакский блок-ІІ (включающий ПшекишБамбакское поднятие и Дудугушскую синклиналь);

- Софийский блок-III (включающий Софийское поднятие и Архыз-Гузерипльскую депрессию);

- Тебердинский блок-IV (в контурах Тебердинского поднятия, включая фррагментарные выходы нижнее-среднеюрских пород в северном его ограничении в верховьях р. Баксан и на западном склоне г. Эльбрус);

- Гондарайский блок-V (ограниченный с югозапада Главным Кавказским разломом, а на севере - Софийско-Клычской депрессией);

- Балкарский блок-VI (западная часть Балкаро-Дигорского поднятия, включающая Эльбрусско-Кубанский-Vla, Шхельдинский-Vlb и Черек-Чегемский-VIc блоки II порядка);

- Урух-Хазнидонский блок-VII (включающий восточную часть Балкаро-Дигорского поднятия, Думалинскую и Хазнидонскую депрессии и западную Урух-Ардонскую часть Дигоро-Осетинской зоны);

- Шхарский блок-VIII (Шхарское поднятие, с севера ограниченное выходами нижне-среднеюрских пород западной части Штулу-Хоресской депрессии);

- Адайхохский блок-IX ( Адайхохское поднятие, с севера ограниченное выходами юрских пород восточной части Штулу-Хоресской депрессии);

- Дарьяльский блок-Х (в центральной части ограниченный крайними южными выходами Дарьяльского массива гранитов, с севера - серией разломов в пределах Дигоро-Осетинской зоны).

Анализ фраций и мощностей бассейна нижне-среднеюрской седиментации показывает, что в течение этого времени происходило последовательное углубление дна бассейна в южной его части и трансгрессия моря в северном направлении $[13,14,17]$, что хорошо фриксируется в пределах восточной части Центрального Кавказа, охватывающей Восточно-Балкарскую и Дигоро-Осетинскую структурно-фациальные зоны, в которых мы видим значительное увеличение мощности образований нижней и средней юры в южном направлении от 1,5 км в пределах Восточно-Балкарской зоны, до 3,5-4 км - в Дигоро-Осетинской зоне. Мощность осадков и их фациальный состав указывают на то, что опускание дна бассейна (фундамента) в южной части Центрального Кавказа (относящегося к южной окраине Скифской эпигерцинской плиты) происходило значительно интенсивнее, нежели в северной его части. Накопление толщ терригенных и вулкано-терригенных осадков происходило прерывисто и относительно длительные периоды опускания дна бассейна и накопления осадков сменялись короткими периодами восходящих движений, как относительно локальных (в аалене), так и региональных (в предбайосское и предкеловейское время), сриксирующихся региональными и локальными размывами и сопровождающимися процессами складкообразования.

Можно предполагать, что именно в периоды погружения фундамента и его наклона в южном направлении (в связи с его более интенсивным погружением в южной части) в результате действия сил субширотного сжатия и при участии тангенциальных право-сдвиговых усилий сформировалась сеть разломов глубокого заложения северо-западной и субширотной ориентировки северного и северо-восточного падения, ориентировочно под углами 45-55 разбивших фундамент центрального сегмента Большого Кавказа (и его периферии?) на серию ромбовидно-линзовидных и линзовидных блоков (различного 


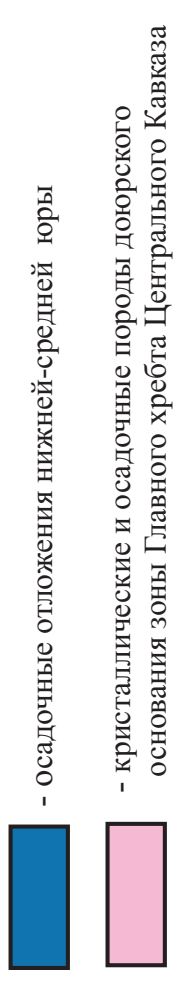


размера и не всегда правильной конфигурации), ориентированных перпендикулярно к оси максимального сжатия.

В дальнейшем появление в южной части фундамента восходящих движений (при сохранении субширотного сжатия и право-сдвиговых усилий) привело к появлению тангенциальных разнонаправленных вертикальных сил на противоположных сторонах ранее оформившихся блоков и их вращению. Вращение сопровождалось скольжением блоков относительно друг друга по плоскостям разломов, ограничивающим блоки, и одновременным увеличением угла их падения. Вращение блоков привело к появлению спорадической (на начальных этапах), а затем и полнопроявленной складчатости в перекрывающих их осадочных толщах.

Ротационные движения тектонических блоков происходили в несколько этапов, соответствующих общепринятым для Большого Кавказа фразам складчатости, - предбайосской, предкелловейской и альпийской. Очевидно, что на киммерийском этапе тектогенеза были сформированы основные депрессии и впадины Центрального Кавказа и получили первоначальное «оформление» перечисленные выше тектонические блоки. Появление новых разломов на более поздних стадиях могло изменять структуру и конфригурацию первоначально образованных блоков. Наиболее интенсивные движения в северной части Центрального Кавказа (Бамбакский, Тебердинский, Софийский, Балкарский и УрухХазнидонский блоки) отвечают, по-видимому, предкелловейской фазе складчатости, в южной (Чугушский, Гондарайский, Шхарский, Адайхохский и Дарьяльский блоки) - альпийской.

В результате вращения блоков и их скучивания произошло:

а) укорочение горизонтальных размеров жесткого гранитно-метаморфического основания;

б) появление разнонаправленных вертикальных движений в перекрывающих менее компетентных породах чехла, которые в сочетании с общим сжатием формируют складчатую (разломно-складчатую) систему, в пределах области проявления ротации блоков. Форма блоков и их размер, по-видимому, напрямую влияют на характер и параметры складок, их взаимоотношение (кулисообразность) и т. д.

Можно предположить, что в общем случае реализация рассматриваемой модели в итоговом виде будет зависеть от реологических свойств пород. В форме блоков она будет реализоваться в пределах компетентных пород («жесткой рамы»), в менее компетентных породах (независимо от того, относятся они к фундаменту или к чехлу) - в форме кулисообразно расположенных («отраженных») поднятий и прогибов.

Резюмируя, следует отметить, что описанный механизм позволяет объяснить перечисленные ранее особенности геологического строения Центрального Кавказа. Из нее следует, что:

- проявление полномасштабной складчатости в чехле возможно и без его срыва с фундамента, и на контактах, даже при крутых углах падения пород чехла, между ними могут сохраняться стратиграфические взаимоотношения;

- образование положительных структур в чехле и более интенсивное сжатие в них может быть связано с вздыманием, в результате ротации, частей блоков фундамента, интервалы же между ними, в силу его жесткости, будут являться «теневыми» зонами, что и обуславливает чередование зон различной интенсивности сжатия и неоднородности деформаций вблизи границы с фундаментом;

- характер, интенсивность и последовательность развития складчатости изменяются в зависимости от угла ротации блоков, если это будет происходить в несколько этапов, мы будем иметь несколько фраз складчатости от спорадической асимметричной до полной нескольких генераций;

- взаимозависимость угла ротации в различных блоках и единая направленность вращения объясняют «моноклинорный» характер залегания чехла в реликтовых останцах в пределах области глубокой эрозии фундамента;

- процесс вращения блоков осуществляется в комплексе с право-сдвиговыми деформациями.

\section{ЗАКЛЮЧЕНИЕ}

Описанные выше представления являются в значительной мере упрощенным вариантом, позволяющим понять принципиальную основу механизма формирования складчатой системы в пределах Центрального Кавказа (сокращения размеров ее жесткого основания) и наметить в общем виде следствия, из него вытекающие. В реальности же этот механизм наблюдается в значительно более сложном виде, что связано с неоднородностью строения и состава пород чехла и фундамента, с реологическим течением пород (особенно в нижней части коры), неоднородностью напряжений, существующих и связанных с ними помимо ротационных вертикальных, горизонтальных и сдвиговых смещений по разломам, с криволинейным характером плоскостей сместителей разломов, подъемом или погружением отдельных блоков, кливажированием толщ чехла и т. д. и т. п.

Влиянием перечисленных фракторов может быть обусловлен неодинаковый угол ротации в 
различных блоках фундамента и его увеличение по направлению к осевой зоне складчатого сооружения, наличие приразломной складчатости.

Вероятно, механизм вращения может осуществляться только при наличии ослабленных зон (вязкого течения?), ограничивающих области, в пределах которых она осуществляется. В общем случае, структуры, подобные описанным, могут являться признаком проявления коллизионных процессов в краевых частях жестких плит.

Одним из наиболее важных моментов ротационно-блокового механизма является признание концепции динамического разлома, то есть разлома с последовательно изменяющимся в процессе его формирования положением плоскости сместителя.

Вращение плоскостей сместителей в процессе последующей деформации - известный в структурной геологии фракт $[3,17,27]$. Как известно [7], тектоническое течение горных масс включает собственно деформацию («стрейн»), параллельный перенос и ротацию. В последнее время особенно большое внимание структурам, связанным с вращением блоков, уделяет М.Л. Копп $[4,5]$. Признание вращательной деформации блоков и ограничивающих их структурных швов расширяет возможности структур- но-геологического анализа конкретных регионов. В частности, помогает объяснить такие сочетания геологических явлений, наблюдаемых в пределах Центрального Кавказа, как складчатость осадочного чехла и блоковый характер фундамента, преимущественно прямолинейный характер крупных разрывных нарушений, их крутое падение, относительную ограниченность проявления надвигов, взаимосвязь магматических явлений и движений фундамента во времени, закономерную пространственную приуроченность магматических тел к границам блоков и крупным разрывным нарушениям, как к участкам утонения фрундамента и одновременно зонам инъецирования магматического расплава. Важным следствием описанного выше является необходимость (для правильного понимания доскладчатой структуры фрундамента) применения палинспастических реконструкций, учитывающих элементы вращения блоков. Влияние тектонических событий, связанных с ротацией блоков фундамента на магматические процессы, обуславливает необходимость их учета при изучении закономерностей и пространственного размещения магматических проявлений и связанных с ними рудно-магматических систем.

\section{ЛИТЕРАТУРА}

1. Адамия М.А., Кипиани Я.Р., Чичуа Г.К. Проблема происхождения складчатости Большого Кавказа // В кн. «Геология и полезные ископаемые Большого Кавказа». - М.: Наука, 1987 е. С. 40-47.

2. Ажгирей Г.Д. Участие древнего кристаллического фундамента в альпийской складчатости Большого Кавказа // Бюл. М.О.И.П. Отдел геология. 1951. Т. 27. С. 60-74.

3. Ажгирей Г.Д, Баранов Г.И., Панов Д.И. Геология Большого Кавказа. - Москва: «Недра», 1976 г.

4. Доттуев С.И. Мезозойско-кайнозойская геодинамика Большого Кавказа // В кн. Геодинамика Кавказа. - Москва: Наука, 1989 а.

5. Гептнер Т.М. Моделирование трещин скалывания в условиях больших деформаций.// Вестник Московского университета. 1970. Сер. 4. Геология № 4. С. 81-89.

6. Гутерман В.Г. Механизмы тектогенеза. - Киев: Наукова думка, 1987.

7. Копп М.Л. Поперечные перемещения в складчатых поясах и связанные с ними структурные рисунки (на примере Альпийско-Гималайского пояса) // Геотектоника, 1991, № 1. С. 21-36.

8. Копп М.Л. Структуры латерального выжимания в Альпийско-Гималайском коллизионном поясе. - Москва: «Научный мир», 1997. 314 с. 9. Копп М.Л. Структуры латерального выжимания в Альпийско-Ги малайском коллизионном поясе. - Москва: «Научный мир», 1997, 314 с. 10. Короновский Н.В., Белов А.А. Геология Большого Кавказа и Предкавказья: достижения и проблемы // В кн. «Геология и полезные ископаемые Большого Кавказа». - М.: Наука, 1987, с.5-21.

11. Милановский E.E., Хаин В.Е. Геологическое строение Кавказа. Изд-во Московского университета, 1963 г.

12. Милановский Е.Е., Короновский Н.В. Геология и полезные ископаемые Большого Кавказа. - Москва: Наука, 1987 г.

13. Объяснительная записка к стратиграфрической схеме юрских отложений Северного Кавказа / Под ред. Безносова Н.В. - М.: Недра, 1973 г.

14. Панов Д.И., Гущин А.И. Структурно-фациальное районирование территории Большого Кавказа для ранней и средней юры и регионально-стратиграфическое расчленение нижнее-среднеюрских отложений // В кн. «Геология и полезные ископаемые Большого Кавказа». - Москва: Наука, 1987. С. 124-139.

15. Расиветаев Л.М. Тектодинамические условия фрормирования структуры Большого Кавказа // В кн. «Геология и полезные ископаемые Большого Кавказа». - Москва, Наука. 1987. С. 69-96.
16. Расцветаев Л.М. О некоторых общих особенностях структуры и альпийской геодинамики Большого Кавказа. // В кн. "Основные проблемы геологического изучения и использования недр Северного Кавказа». - Ессентуки, 1995. С. 257-260.

17. Ростовиев К.О. Юра Кавказа. - Санкт-Петербуре: «Наука», 1992 г. 18. Карл К.Сейферт. Милонитовые породы // В кн. «Структурная геология и тектоника плит». - М.: Мир, 1991. С. 55-74.

19. Сомин М.Л., Видяпин Ю.П. Соотношение фундамент - чехол и проблема происхождения складчатости Большого Кавказа // В кн. "Геология и полезные ископаемые Большого Кавказа». - М.: Наука, 1987 2. С. 62-69.

20. Сомин М.Л. Структурная позиция и геодинамические условия формирования метаморфических комплексов Большого Кавказа и Кубы // Диссертация в форме научного доклада на соискание ученой степени доктора геолого-минералогических наук. Москва, 2007. 21. Шевченко В.И. Происхождение структур горизонтального сжатия в складчатом сооружении. - Москва: Наука, 1984 г. 159 с.

22. Шемпелев А.Г. Разломно-блоковая тектоника Северного Кавказа по геофизическим данным // Геологический журнал. Киев, 1982. № 4. C. $97-108$.

23. Шемпелев А.Г., Кухмазов С.У., Чотчаев Х.О., Невский Л.Н. Структура Большого Кавказа - результат пологого надвига земной коры Скифской плиты на консолидированную кору микроплит Южного Кавказа // Геология и геофизика Юга России, № 4, 2015. C. 129-145.

24. Шенгелия Д.М., Кориковский СП. и др. Петрология метаморфических комплексов Большого Кавказа. Москва: Наука, 1984 г. 232 с. 25. Шолпо В.Н., Рогожин Е.А., Гончаров М.А. Складчатость Большого Кавказа. - М.: Наука, 1993 г., 192 с.

26. Хаин В.Е.,Милановский Е.Е. и др. Геологическое строение Кавказа. - МГУ, 1963 г. 358 с.

27. Ли Сы-Гуан, Сунь Дянь-Цин, У Лей-Бо и др. Вихревые и дру гие структуры вращения и проблемы сочетания тектонических систем (перевод с китайского). - Москва, 1960 г.

28. Kozonovsкy N. V., Demina L.I. Simonov D.A. Late-Cenozoic collision volcanism of the Caucasus. Moscow State University, Russia. INTAS Research project № 94-3881.

29. Freund R. Rotation of strike-slipe faults in Sistan, Southeast Iran. Qeol. 1970 № 2. 


\title{
UNIDIRECTIONAL ROTATION OF THE FOUNDATION BLOCKS, AS A MECHANISM FOR REDUCING THE BASEMENT SIZE FOLD SYSTEM (FOR EXAMPLE, THE CENTRAL CAUCASUS) \\ Part № 2 \\ Y.A. Kirichko
}

Department of Geology and Mineral Resources of the North Caucasus Federal District. Essentuky, Stavropol region.

\begin{abstract}
For the Cimmerian and Alpine stages in the development of the Central Caucasus (CC) considered mechanism of folding, taking into account the nature of the block structure of the basement, occurrence mantle relics and especially manifestations of folded deformations. Determining the mechanism of formation is a folding rigid unidirectional rotation of the foundation blocks. The rotation mechanism is seen as part of a three-layer model of the Earth's crust that included the following layers: the bottom - high ductility; medium - hard, broken obliquely intersecting planes at an angle of $45^{\circ}$ at the top and a series rhombohedra - Plastic responsible sedimentary cover. Formation of folding during the rotation of the foundation blocks due to the presence of horizontal compression forces, reduction of the surface of the hard base and the presence of synchronous current divergent vertical forces acting on the block boundaries. Within the CC released 10 major large blocks, with signs of the rotary mechanism, much of which previously stood as elevations and depressions Rotary mechanism allows the block to explain the main features of the geological structure of the CC: the manifestation of a full-scale folding in the bag, while maintaining the stratigraphic relationships between cover and basement; heterogeneity of manifestations of deformation in a case, and others. Described representation is a simplified version, which allows to understand the conceptual framework of the proposed mechanism and outline consequences arising from it.

An essential element of the rotary mechanism of the block is the recognition of the concept of fault with consistently changing position shifter plane. Recognition of rotational deformation blocks and limiting their structural joints enhances the structural and geological analysis.

Keywords: Central Caucasus, foundation, cover, depression, depression, elevation, mechanism of folding, the reduction of the size of the hard basement, the rotation of the blocks of basement, dynamic fault.
\end{abstract}

\section{REFERENCES}

1. Adamiya M.A. Kipiani Ya.R. Chichua G.K. Problema proiskhozhdeniya skladchatosti Bol'shogo Kavkaza. // V kn. "Geologiya i poleznye iskopaemye Bol'shogo Kavkaza». - M.: Nauka, 1987 g. S. 40-47.

2. Azhgirey G.D. Uchastie drevnego kristallicheskogo fundamenta v al'piyskoy skladchatosti Bol'shogo Kavkaza. Byul. M.O.I.P. Otdel geologiya. 1951. T. 27. S. 60-74.

3. Azhgirey G.D, Baranov G.I., Panov D.I. Geologiya Bol'shogo Kavkaza. - Moskva: «Nedra», $1976 \mathrm{~g}$

4. Dottuev S.I. Mezozoysko-kaynozoyskaya geodinamika Bol'shogo Kavkaza // V kn. Geodinamika Kavkaza. - Moskva: Nauka, $1989 \mathrm{~g}$.

5. Geptner T.M. Modelirovanie treshchin skalyvaniya usloviyakh bol'shikh deformatsiy. // Vestnik Moskovskogo universiteta. 1970. Ser. 4. Geologiya № 4. S. 81-89.

6. Guterman V.G. Mekhanizmy tektogeneza. - Kiev: Naukova dumka, 1987.

7. Kopp M.L. Poperechnye peremeshcheniya v skladchatykh poyasakh i svyazannye s nimi strukturnye risunki (na primere Al'piysko-Gimalayskogo poyasa) // Geotektonika, 1991, № 1. S 21-36.

8. Kopp M.L. Struktury lateral'nogo vyzhimaniya v Al'piyskoGimalayskom kollizionnom poyase. - Moskva: «Nauchnyy mir», 1997. $314 \mathrm{~s}$.

9. Kopp M.L. Struktury lateral'nogo vyzhimaniya v Al'piyskoGimalayskom kollizionnom poyase. - Moskva: «Nauchnyy mir», 1997, $314 \mathrm{~s}$.

10. Koronovskiy N.V., Belov A.A. Geologiya Bol'shogo Kavkaza i Predkavkaz'ya: dostizheniya i problemy. // V kn. "Geologiya poleznye iskopaemye Bol'shogo Kavkaza». - M.: Nauka, 1987, s.5-21.

11. Milanovskiy E.E., Khain V.E. Geologicheskoe stroenie Kavkaza. - Izd-vo Moskovskogo universiteta, $1963 \mathrm{~g}$.

12. Milanovskiy E.E., Koronovskiy N.V. Geologiya i poleznye iskopaemye Bol'shogo Kavkaza. - Moskva: Nauka, $1987 \mathrm{~g}$ 13. Ob"yasnitel'naya zapiska k stratigraficheskoy skheme yurskikh otlozheniy Severnogo Kavkaza. / Pod red. Beznosova N.V. - M.: Nedra, 1973 g.

14. Panov D.I., Gushchin A.I. Strukturno-fatsial'noe rayonirovanie territorii Bol'shogo Kavkaza dlya ranney i sredney yury i regional'no-stratigraficheskoe raschlenenie nizhneesredneyurskikh otlozheniy. // V kn. "Geologiya i poleznye iskopaemye Bol'shogo Kavkaza». - Moskva: Nauka, 1987. S. 124-139.

15. Rastsvetaev L.M. Tektodinamicheskie usloviya formirovaniya struktury Bol'shogo Kavkaza // V kn. "Geologiya i poleznye iskopaemye Bol'shogo Kavkaza». - Moskva, Nauka. 1987. S. 69-96.

16. Rastsvetaev L.M. O nekotorykh obshchikh osoben-nostyakh struktury i al'piyskoy geodinamiki Bol'shogo Kavkaza. // V kn. "Osnovnye problemy geologicheskogo izucheniya i ispol'zovaniya nedr Severnogo Kavkaza». - Essentuki, 1995. S. 257-260.

17. Rostovtsev K.O. Yura Kavkaza. - Sankt-Peterburg: "Nauka», $1992 \mathrm{~g}$.

18. Karl K.Seyfert. Milonitovye porody. // V kn. "Strukturnaya geologiya i tektonika Plit». - M.: Mir, 1991. S. 55-74.

19. Somin M.L., Vidyapin Yu.P. Sootnoshenie fundament chekhol i problema proiskhozhdeniya skladchatosti Bol'-shogo Kavkaza // V kn. "Geologiya i poleznye iskopaemye Bol'shogo Kavkaza». - M.: Nauka, 1987 g. S. 62-69.

20. Somin M.L. Strukturnaya pozitsiya i geodinamicheskie usloviya formirovaniya metamorficheskikh kompleksov Bol'shogo Kavkaza i Kuby. // Dissertatsiya v forme nauchnogo doklada na soiskanie uchenoy stepeni doktora geologomineralogicheskikh nauk. Moskva, 2007.

21. Shevchenko V.I. Proiskhozhdenie struktur gorizontal'nogo szhatiya v skladchatom sooruzhenii. - Moskva: Nauka, 1984 g. $159 \mathrm{~s}$.

22. Shempelev A.G. Razlomno-blokovaya tektonika Severnogo Kavkaza po geofizicheskim dannym // Geologicheskiy zhurnal. Kiev, 1982. № 4. S. 97-108.

23. Shempelev A.G., Kukhmazov S.U., Chotchaev Kh.O., Nevskiy L.N. Struktura Bol'shogo Kavkaza - rezul'tat pologo-go nadviga zemnoy kory Skifskoy plity na konsolidirovannuyu koru mikroplit Yuzhnogo Kavkaza. // Geologiya i geofizika Yuga Rossii, № 4, 2015. S. 129-145.

24. Shengeliya D.M., Korikovskiy SP. $i$ dr. Petrologiya metamorficheskikh kompleksov Bol'shogo Kavkaza. Moskva: Nauka, 1984 g. $232 \mathrm{~s}$

25. Sholpo V.N., Rogozhin E.A., Goncharov M.A. Skladchatost' Bol'shogo Kavkaza. - M.: Nauka, 1993 g., $192 \mathrm{~s}$.

26. Khain V.E.,Milanovskiy E.E. i dr. Geologicheskoe stroenie Kavkaza. - MGU, 1963 g. $358 \mathrm{~s}$

27. Li Sy-Guan, Sun' Dyan'-Tsin, U Ley-Bo idr. Vikhrevye i drugie struktury vrashcheniya i problemy sochetaniya tektonicheskikh sistem (perevod s kitayskogo). - Moskva, $1960 \mathrm{~g}$.

28. Kogopovsku N. V., Demina L.I. Simonov D.A. Late-Cenozoic collision volcanism of the Caucasus. Moscow State University, Russia. INTAS Research project № 94-3881.

29. Freund R. Rotation of strike-slipe faults in Sistan, Southeast Iran. Qeol. 1970 № 2. 